\title{
miR-21 is involved in norepinephrine- mediated rat granulosa cell apoptosis by targeting SMAD7
}

\author{
Li Zhang*, Jie Gao* and Sheng Cui
}

State Key Laboratory of Agrobiotechnology, College of Biological Sciences, China Agricultural University, Beijing, China

*(L Zhang and J Gao contributed equally to this work)

Correspondence should be addressed to S Cui

Email

cuisheng@cau.edu.cn

\begin{abstract}
Substantive evidence has indicated that the sympathetic innervation contributes to the regulation and development of ovarian functions. Norepinephrine (NE) is one of the major neurotransmitters contained in the extrinsic ovarian sympathetic nerves and is thought to be a potent moderator of ovarian functions such as steroidogenesis and granulosa cell proliferation or apoptosis. However, the mechanisms of NE regulation of granulosa cell apoptosis in the rat ovary are rare. Real-time PCR and Western blot results show that NE regulates the expression of miR-21 in primary granulosa cells in a dose-dependent manner. Additionally, we found that miR-21 is involved in NE-mediated rat granulosa cells apoptosis and blocks granulosa cell apoptosis by targeting Smad7, a transforming growth factor-beta-inducible mediator of apoptosis in granulosa cells. In primary granulosa cells, a combined treatment of NE and TGF- $\beta$ increased apoptosis and decreased miR-21 expression, but increased SMAD7 protein levels. We also demonstrated that NE regulates miR-21 by coupling to $\alpha_{1 A}$-adrenergic receptor ( $\left.\alpha_{1 A}-A R\right)$. This is the first demonstration that NE controls the reproductive functions by modulating the expression of miR-21 and promoting TGF- $\beta$-induced granulosa cell apoptosis. Such NE-mediated effects could be potentially used for regulating the reproductive processes and for treating reproductive disorders.
\end{abstract}
Key Words
- miR-21
- ovary
- apoptosis
- NE
- SMAD7

Journal of Molecular

Endocrinology

(2017) 58, 199-210

\section{Introduction}

The rat ovaries receive their sympathetic innervation from two sources. One is the ovarian plexus nerve, which travels along the ovarian artery, and the other is the superior ovarian nerve (SON), which is associated with the suspensory ligament (Mayerhofer et al. 1997, D'Albora et al. 2002). The extrinsic innervation of the gland has been shown to regulate ovary-specific functions, such as steroidogenesis and early follicular development (Skarzynski 1993, Mayerhofer et al. 1997). The regulatory functions are mainly exerted via NE
(Lawrence \& Burden 1980). Previous studies have shown that ovarian non-neuronal, endocrine granulosa cells can both take up and release NE in a regulated manner (Greiner et al. 2008). Adrenergic innervation can stimulate steroid secretion and promote granulosa cell proliferation by $\mathrm{NE}$ binding to the $\beta$-adrenergic receptor ( $\beta$-AR) or $\alpha_{1 \mathrm{~A}}$-AR (Lawrence \& Burden 1980, Lara et al. 2002). NE also facilitates follicular development, as denervation of the ovaries inhibits follicular growth (Advis et al. 1989). In the rat, the importance of its interrelation on the 
ovarian steroidogenesis and apoptosis on dioestrus II has been demonstrated (Bronzi et al. 2015). However, the reports about signaling pathways of NE-regulating ovary functions remain few.

MicroRNAs (miRNAs) are 20-24 nt endogenous nonprotein encoding RNAs and have emerged as important mediators of cellular differentiation, proliferation and apoptotic events (Otsuka et al. 2008, Donadeu et al. 2012). There are scant data about the function of microRNA in the ovary. One such miRNA, miR-378, regulates estradiol production by targeting aromatase (Xu et al. 2011). miR-224 is involved in TGF- $\beta$-induced granulosa cell proliferation and granulosa cell functions by targeting SMAD4 (Yao et al. 2010). MicroRNA-21 was shown to regulate granulosa cell apoptosis, and in vivo knockdown of miR-21 causes an increase in apoptosis (Carletti et al. 2010). Although miR-21's function of blocking granulosa cell apoptosis has been established in the ovary, the signaling pathway of miR-21 in the rat ovary is unknown.

Smad7 is a general signaling antagonist for both the TGF- $\beta$ and bone morphogenetic protein (BMP) family (Park 2005). An altered expression of Smad7 is associated with several human disease processes, including cancer, tissue fibrosis and inflammatory diseases (Briones-Orta et al. 2011). A previous study has reported that overexpression of Smad7 in granulosa cells markedly increases apoptosis, and when Smad7 expression is reduced, TGF- $\beta$-induced apoptosis is blocked (Quezada et al. 2012). However, whether Smad7 regulates NE's granulosa cell function is still unknown.

In this study, we initially examined miR-21 expression in the rat ovary and demonstrated that miR-21 is mainly located in granulosa cells. Upon further research, we showed that miR-21 functions as a mediator of the NE signaling pathway by targeting Smad7 thus regulating granulosa cells apoptosis. These findings suggest that miR-21 plays a key role in regulating granulosa cell apoptosis by targeting Smad7. Additionally, NE regulates miR-21 expression by binding to $\alpha_{1 \mathrm{~A}}$-AR and is involved in TGF $\beta / S M A D$ signaling.

\section{Materials and methods}

\section{Animals and tissue collections}

Rats (Wistar) for this study were purchased from the Animal Institute of the Chinese Medical Academy (Beijing, China) and raised in standard temperature $\left(25 \pm 1^{\circ} \mathrm{C}\right)$ and light (12-h light, 12-h darkness cycle) conditions. All animal procedures were approved by the Chinese
Association for Laboratory Animal Sciences. Female rats at approximately 21 days were injected intraperitoneally with $10 \mathrm{U}$ of pregnant mare serum gonadotropin (PMSG) to stimulate follicular development for $46 \mathrm{~h}$. The rats were killed by cervical dislocation. For in situ hybridization and immunohistochemistry, the collected rat ovaries were fixed for $1 \mathrm{~h}$ in $4 \%$ (paraformaldehyde) PFA at room temperature (RT), and then placed in 30\% sucrose at $4^{\circ} \mathrm{C}$ overnight. The tissues were embedded in 'TissueTek' O.C.T. compound (TaKaRa Biotechnology), and $10 \mu \mathrm{m}$ thick sections were cut using a cryostat.

\section{In situ hybridization}

miR-21 in situ hybridization (ISH) was carried out using digoxigenin (DIG)-labeled locked nucleic acid (LNA) probes. Rno-miR-21-5p miRCURY LNA microRNA detection probes (TCAACATCAGTCTGATAAGRANULOSA CELLTA) were purchased from Exiqon (MA, USA). We labeled the LNA probes with digoxingenin using a DIG oligonucleotide tailing kit (Roche Diagnostics) following the manufacturer's instructions. miR-21 ISH assays were carried out as described previously (Obernosterer et al. 2007). Briefly, the dried slides were fixed in 4\% PFA for $10 \mathrm{~min}$ at room temperature and then washed twice for $3 \mathrm{~min}$ in $1 \times$ phosphate-buffered saline (PBS). The fixed sections were subjected to acetylation for $10 \mathrm{~min}$, followed by PBS washes. The slides were pre-hybridized for $8 \mathrm{~h}$ at RT, and the hybridization was carried out at $51^{\circ} \mathrm{C}$ overnight. After stringency washings using $5 \times$ saline sodium citrate (SSC) for $10 \mathrm{~min}$ and $0.2 \times$ SSC for $1 \mathrm{~h}$ at $60^{\circ} \mathrm{C}$, the slides were incubated in a blocking solution for $1 \mathrm{~h}$ at RT, which was followed by incubation with alkaline phosphatase (AP)-conjugated antibody to digoxingenin at $4^{\circ} \mathrm{C}$ overnight. After PBS and alkaline phosphates buffer washes, the slides were incubated in nitro blue tetrazolium (NBT) and 5-bromo-4-chloro-3-indolyl phosphate (BCIP) in the darkness until the prospective intensity of staining was reached. The sections were examined under a DMRB light microscope (Leica).

\section{Immunohistochemistry}

For immunohistochemistry (IHC), the ovary sections were dewaxed, rehydrated and treated with $10 \%$ normal goat serum in PBS to block nonspecific binding sites. For $\alpha_{1 \mathrm{~A}}$-AR staining, an antibody against the adrenergic receptor (1:50; sc-1477, Santa Cruz Biotechnology) was incubated at $4^{\circ} \mathrm{C}$ for $12 \mathrm{~h}$. In the negative control group, the antibody against the adrenergic receptor was replaced by

Published by Bioscientifica Ltd 
PBS. The sections were then incubated with a biotinylated goat anti-rabbit IgG (1:200; Zymed Laboratories) and horseradish peroxidase (HRP)-conjugated streptavidin (1:500, Jackson ImmunoResearch Laboratories) at RT for $2 \mathrm{~h}$. Visualization was done using diaminobenzidine (DAB) with hematoxylin counterstaining.

\section{Cell culture}

For each individual studies, 10 female rats at approximately 21 days were killed by cervical dislocation after injected intraperitoneally with $10 \mathrm{U}$ PMSG to stimulate follicular development for $46 \mathrm{~h}$. Then, the isolation of oocytes and granulosa cells were carried out as described previously (Hanoux et al. 2007, Fiedler et al. 2008, Teng et al. 2015). Under sterile conditions, cumulus-oocyte complexes (COCs) were collected immediately by puncturing follicles from the isolated ovary. The follicular fluid and COCs sank to the bottom of the dishes. The follicular fluid containing COCs was poured into a $90-\mathrm{mm}$ petri dish containing oocyte washing medium consisting of HEPES-buffered TCM 199 supplemented with 10\% (v/v) fetal calf serum (FCS). The COCs, with selected under a stereomicroscope (Nikon), then were used for RNA extraction. Meanwhile, granulosa cells were aspirated from the large follicles. This pellet was dispersed, and then filtration and centrifugation were carried out. The granulosa cells were harvested, washed and resuspended in DMEM/F12 media containing 10\% FBS (Gibco). The cells were then counted and the viability was assessed. For the assay, cells were plated $\left(1.0 \times 10^{5}\right.$ cells/well $)$ onto eight $35 \mathrm{~mm}$ dishes for $24 \mathrm{~h}$ at $37^{\circ} \mathrm{C}$ in a humidified atmosphere of $5 \% \mathrm{CO}_{2}$. After being cultured for $48 \mathrm{~h}$, the primary granulosa cells were transfected.

The 293T cell line was grown in Dulbecco's modified Eagle's medium (DMEM; Gibco) containing 10\% (V/V) fetal bovine serum (FBS; Gibco) and $1 \%$ penicillin streptomycin. The cells were also incubated at $37^{\circ} \mathrm{C}$ in a humidified atmosphere of $5 \% \mathrm{CO}_{2}$.

\section{MicroRNA and siRNA transfections}

For the assay, cells were plated $\left(1.0 \times 10^{5}\right.$ cells/well $)$ onto $35 \mathrm{~mm}$ dishes for $24 \mathrm{~h}$ at $37^{\circ} \mathrm{C}$ in a humidified atmosphere of $5 \% \mathrm{CO}_{2}$. The transfections of the miR-21 inhibitor or mimics were performed using Lipofectamine2000 (Invitrogen) according to the manufacturer's instructions. Six hours after transfection, the cells were collected for real-time PCR or cell apoptosis analysis. The oligos (nc inhibitor (nc-in), miR-21 inhibitor (miR-21-in), nc mimics (nc-mi) and miR-21 mimics (miR-21-mi)) were used for the cell transfection were purchased from RibBio (Guangzhou, China).

\section{Real-time PCR}

According to the protocol provided by the manufacturer, the total RNA of the granulosa cells was isolated using the TRIzol reagent (TaKaRa). U6 RNA was used for normalization of microRNA expression. Reverse transcriptase reactions contained the purified total RNA $(0.3 \mu \mathrm{g}), 50 \mathrm{nM}$ reverse transcription (RT) primer (the RT-miR-21 stem-loop primer: CTCAACTGGTGTCGTGGAGTCGGAATTCAGTTGAGTCAACATC and the RT-U6 stem-loop primer: AACGCTTCACGAATTTGCGT). M-MLV reverse transcriptase (Promega) was used according to the manufacturer's instructions. The $15 \mu \mathrm{L}$ reactions were incubated in a DNA Thermal Cycler 4800 for $30 \mathrm{~min}$ at $16^{\circ} \mathrm{C}, 30 \mathrm{~min}$ at $42^{\circ} \mathrm{C}$ and $5 \mathrm{~min}$ at $85^{\circ} \mathrm{C}$. Real-time PCR was performed using a standard TaKaRa SYBR Premix Ex Taq protocol on an Applied Biosystems 7500 Real-time PCR System (Applied Biosystems). The primer sequences are listed in Table 1, and the conditions were as follows: $95^{\circ} \mathrm{C}$ for $10 \mathrm{~min}$, followed by 40 cycles of $95^{\circ} \mathrm{C}$ for $15 \mathrm{~s}$ and $60^{\circ} \mathrm{C}$ for $1 \mathrm{~min}$. The relative abundance of the genes was determined using the ABI PRISM 7500-equipped software (Applied Biosystems). All the experiments were performed in at least triplicate.

Table 1 Primers used for real-time PCR in this study.

\begin{tabular}{|c|c|}
\hline Gene & Sequence of primers $\left(5^{\prime} \rightarrow 3^{\prime}\right)$ \\
\hline \multirow[t]{2}{*}{$\alpha_{1 A}-A R$} & F: ACTCAGAGCAAGTGACGCTC \\
\hline & R: ACGGTTTCCGAAGGCTTGAA \\
\hline \multirow[t]{2}{*}{$\alpha_{1 \mathrm{~B}}-\mathrm{AR}$} & F: CATGAGGACACCCTCAGCAG \\
\hline & R: TGGAGAACAGGGAGCCAAGC \\
\hline \multirow{2}{*}{$\alpha_{1 D^{-}}-A R$} & F: AAGTTTTGGTGGCGTATTGGA \\
\hline & R: GAAGTGATGGGCACAGACAGG \\
\hline \multirow[t]{2}{*}{$\beta_{2}-\mathrm{AR}$} & F: CTGCCTTCAATCCTCTTATCT \\
\hline & R: GTCTGTCCTACCGTTGCTGTT \\
\hline \multirow[t]{2}{*}{ SMAD7 } & F: TATGATGCGGATTTTTGGTTGTG \\
\hline & R: TGACTCTTGCTTCCCGTTTTTTGT \\
\hline \multirow[t]{4}{*}{ miR-21 } & RT: CTCAACTGGTGTCGTGGAGTCGG \\
\hline & CAATTCAGTTGAGTCAACATC \\
\hline & F: GTATGCTCATCCTAGCTTATCAGACT \\
\hline & R: GTATGCTCATCCTAGCTTATCAGACT \\
\hline \multirow[t]{2}{*}{ U6 } & F: CTCGCTTCGGCAGCACA \\
\hline & R: AACGCTTCACGAATTTGCGT \\
\hline \multirow[t]{2}{*}{ Bax } & F: TTTCATCCAGGATCGAGCAGG \\
\hline & R: GCAAAGTAGAAGAGGGCAACCAC \\
\hline \multirow[t]{2}{*}{$\mathrm{Bcl}-2$} & F: CTACCGTCGTGACTTCGCA \\
\hline & R: TACCCAGCCTCCGTTATCC \\
\hline
\end{tabular}

$F$, forward primer; $R$, reverse primer.

Published by Bioscientifica Ltd 


\section{Western blot}

Granulosa cells werelysed with radio immunoprecipitation (RIPA) buffer $(50 \mathrm{mM}$ Tris- $\mathrm{HCl}, \mathrm{pH} 7.4,150 \mathrm{mM} \mathrm{NaCl}$, 1\% Triton $\mathrm{X}-100,1 \%$ sodium deoxycholate, $0.1 \%$ SDS) containing $1 \mathrm{mM}$ phenylmethanesulfonyl fluoride (PMSF). The protein concentration of each group was determined using a BCA assay reagent (Vigorous Biotechnology, Beijing, China) according to the manufacturer's recommendations. Equal amounts of protein $(50 \mu \mathrm{g})$ were electrophoresed on $11 \%$ sodium dodecyl sulfate-polyacrylamide gel (SDS-PAGE), and the bands were transferred to a polyvinylidene difluoride (PVDF) membrane (Bio-Rad Laboratories). The membrane was blocked with $5 \%(\mathrm{w} / \mathrm{v})$ non-fat dry milk in $0.05 \mathrm{M} \mathrm{pH}$ 7.4 Tris-buffered saline (TBS) for $3 \mathrm{~h}$ and incubated with a SMAD7 antibody (1:1000, ab124890, Abcam), and as an internal control, a GAPDH antibody (1:10,000, Ambion) overnight at $4^{\circ} \mathrm{C}$. The PVDF membrane was then washed 3 times for $30 \mathrm{~min}$ in TBST $(0.1 \%$ Tween 20 in TBS) and incubated for $2 \mathrm{~h}$ with horseradish peroxidaseconjugated goat anti-rabbit IgG. After washing for 30 min with 3 changes of TBST, the membrane was treated with the pierce ECL 2 Western Blot Substrate (Thermo Scientific). The relative intensity of each blot was assessed and analyzed using the AlphaImager 2200 Software package. The intensity values pertaining to each group were normalized against the optical density of GAPDH corresponding to the same group within a single gel and expressed in terms of the means \pm s.e.M. of 3 independent experiments.

\section{Luciferase reporter assay}

The dual-luciferase reporter genes were constructed using the psiCHECKTM-2 vector (Promega) and the 3'-UTR sequences of rat Jag1 and Smad7. The Smad7 3'UTR fragment cloning was done using an overlap PCR (Table 2), and it was introduced between the NotI and Xhol sites of the Renilla luciferase 3'UTR. The firefly luciferase vector was used for an internal reference. 293T cells were transfected using Lipofectamine 2000 with a mixture containing $200 \mathrm{ng} / \mathrm{mL}$ of the dual-luciferase reporter plasmid and $40 \mathrm{nM}$ of miR-21 mimics. Cells transfected with the mut-Smad7 vector served as controls for normalization. Luciferase activity was measured by a ModulusTMII microplate multimode reader (Promega) $24 \mathrm{~h}$ after transfection using a Dual-Lucy Assay Kit (Vigorous Biotechnology Beijing Co.). All transfections were repeated independently at least three times.
Table 2 The JAG1/SMAD7-3'UTR sequences containing the miR-21-binding site were constructed into a psi-CHECK 2 vector.

JAG1-3'UTR: attcgtatgtaatgctgaaccacttgtagatttgatttcattgttgttgtctactgcatttagggagtattctaataagctagatg

aatacttgaaccataaaatgtccagttagagcactgtttagattggccatagagtacactgcctgccttaagtg

Mut-JAG1-3'UTR: attcgtatgtaatgctgaaccacttgtagatttgatttcattgttgttgtctactgcatttagggagtattctatatctgaagatgaatacttgaaccataaaatgtccagttagagcactgtttagattggccatagagtacactgcctgccttaagtg

SMAD7-3'UTR: ccttctctcggctcatacactcgtatgatactctgacactgttcttggctcaatgagcatgctcacactttaatataagctatt

tttctaactacaaaggtttaaaaatgaacaagagaggcgttctcatcggaaatttagcatcgtagtgctttgagag

Mut-SMAD7-3'UTR: ccttctctcggctcatacactcgtatgatactctgacactgttcttggctcaatgagcatgctcacactttaattagtatcatttttctaactacaaaggtttaaaaatgaacaagagaggcgttctcatcggaaatttagcatcgtagtgctttgagag

The sequences in red indicate binding sites of miR-21

\section{Cell counting}

For the estimation of granulosa cell apoptosis, we obtained the micrographs of sections for cleaved caspase-3 immunohistochemistry with a Leica DMLB microscope equipped with a Leica DFC320 camera (Leica) under a $20 \times$ and $40 \times$ magnification objective, respectively. The cleaved caspase-3 IHC-positive cells and total cells from the micrographs were counted using the manual counter function of Alphamager 2200 software. Cell counting was performed by two investigators, and the results are expressed as the percentages of cleaved caspase- 3 immunepositive cells.

\section{Statistical analysis}

All experiments were independently performed more than three times. All data were analyzed using SAS 9.0. The values are presented as the means \pm s.e.M. One-way ANOVA was used for statistical comparisons among multiple groups. ANOVA was performed using GraphPad Prism 4.0 (GraphPad Software). For statistical comparisons between the two groups, the Student's two-tailed $t$ test was used. A value of $P<0.05$ or $P<0.01$ was considered to be statistically significant.

\section{Results}

miR-21 and the adrenergic receptor are expressed in the rat ovary

To study whether miR-21 is involved in mediating NE's effects on granulosa cells apoptosis, we initially examined

Published by Bioscientifica Ltd 
A

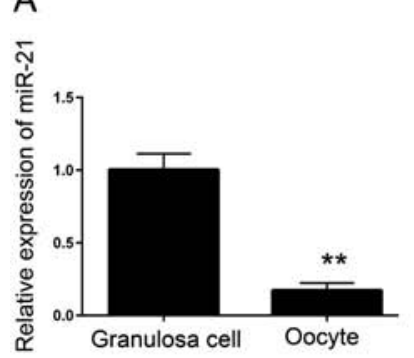

B $\quad$ miR-21
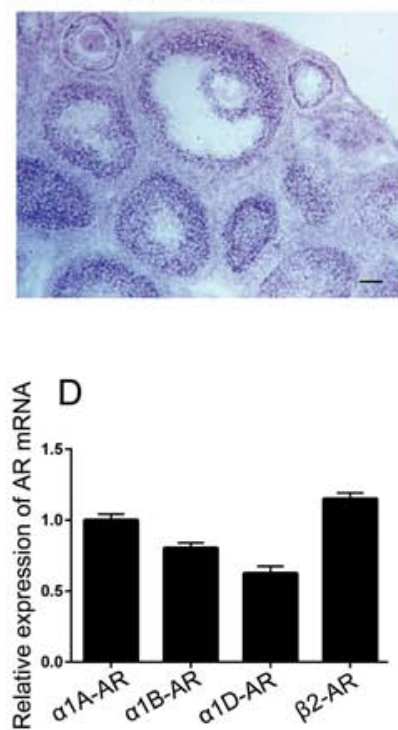

C

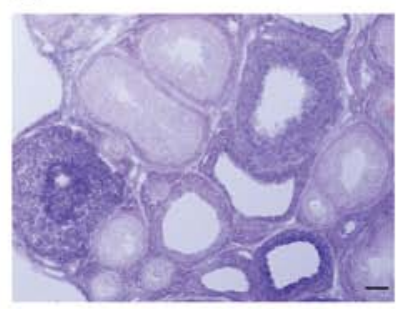

E

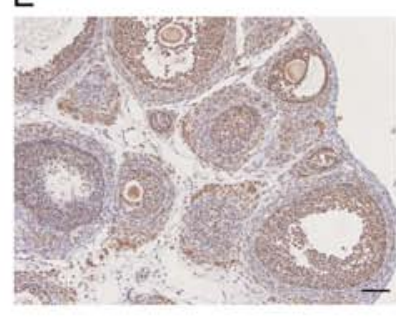

scramble

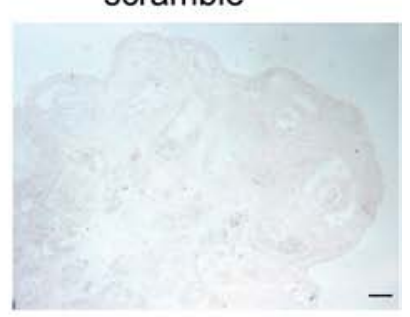

Negative control

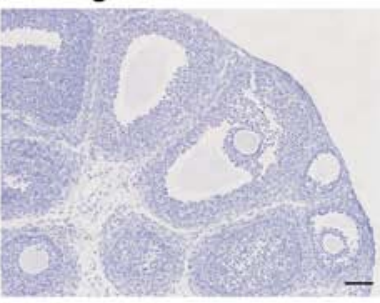

Figure 1

miR-21 and the adrenergic receptors are expressed in rat ovary. (A) Relative miR-21 expression levels in isolated granulosa cells and oocytes by real-time PCR. The experiments were repeated at least three times and normalized to their respective control. Data are shown as means \pm S.E.M. ( $n \geq 3$ ).

$* * P<0.01$. (B) Localization of miR-21 in the rat ovary using LNA ISH. (C) Localization of miR-21 in the rat ovary which from an animal model for the study of follicular atresia using LNA in situ hybridization. (D) Gene expression of adrenergic receptors in granulosa cells. The experiments were repeated at least three times. Data are shown as means \pm S.E.M. $(n \geq 3)$. (E) The expression of the $\alpha_{1 \mathrm{~A}}$-adrenergic receptor in the rat ovary using IHC. All scale bars represent $50 \mu \mathrm{m}$.

the expression of miR-21 and the adrenergic receptors $\left(\alpha_{1 \mathrm{~A}}-\mathrm{AR}, \alpha_{1 \mathrm{~B}}-\mathrm{AR}, \alpha_{1 \mathrm{D}}-\mathrm{AR}\right.$ and $\left.\beta_{2}-\mathrm{AR}\right)$ in the rat ovary and granulosa cells by real-time PCR, ISH and IHC. The realtime PCR and ISH results showed that miR-21 was expressed only in the granulosa cells, but not in the oocyte (Fig. 1A and $\mathrm{B})$. In addition, we found that there is less expression of miR-21 in the rat ovaries from the animal model for the study of follicular atresia (Fig. 1C). Real-time PCR and IHC results showed that the adrenergic receptors mainly localized to granulosa cells in the rat ovary (Fig. 1D and E). These data show that miR-21 and adrenergic receptors are co-expressed in rat granulosa cells.

\section{NE suppresses miR-21 expression and induces rat granulosa cell apoptosis}

To investigate a potential functional relationship between $\mathrm{NE}$ and miR-21 in regulating rat granulosa cells apoptosis, we assessed the effects of NE on miR-21 expression and apoptosis in rat granulosa cells. Cultured rat granulosa cells were treated with 0 (control), $0.1,1$ and $10 \mu \mathrm{mol} / \mathrm{L}$ $\mathrm{NE}$ for $24 \mathrm{~h}$, and miR-21 levels were, respectively, detected by using real-time PCR. The results showed that $10 \mu \mathrm{mol} / \mathrm{L}$ NE significantly decreased miR-21 expression, but 0.1 and $1 \mu \mathrm{mol} / \mathrm{L} \mathrm{NE}$ had no obvious effects on
miR-21 expression (Fig. 2A). Additionally, miR-21 levels were, respectively, assayed after 0 -h (control), 12-h and 24-h treatment, and the effect of NE on miR-21 expression was measured. The NE treatment decreased miR-21 levels about 58\% and 49\%, respectively (Fig. 2B). These data demonstrate that NE regulates the expression of miR-21 in a dose- and time-dependent manner. It is known that there are two kinds of commonly used adrenergic receptors (AR), AR- $\alpha 1$ and $A R-\beta 2$, by $N E$ in rat ovary. To determine which AR couples with NE, we separately added $10 \mu \mathrm{mol} / \mathrm{L}$ of two AR inhibitors to granulosa cells. The inhibitors are prazosin for AR- $\alpha 1$ and butoxamine for AR- $\beta 2$. The cells were then additionally treated with $\mathrm{NE}$ for $24 \mathrm{~h}$. The results show that miR-21 repression was not only relieved but also highly stimulated by prazosin (Fig. 2C).

To investigate whether NE has a role in regulating granulosa cells apoptosis, we tested the effect of $\mathrm{NE}$ treatment on granulosa cells apoptosis by counting the cleaved caspase3-positive cells. We counted cleaved caspase3-positive cells in more than 5000 cells per treatment. There was roughly $18 \%$ cleaved caspase3positive cell in $10 \mu \mathrm{mol} / \mathrm{L}$ NE more than that in control group (Fig. 2E) $(P<0.05)$. These data demonstrate that $10 \mu \mathrm{mol} / \mathrm{L}$ NE induces rat granulosa cells apoptosis.

Published by Bioscientifica Ltd 
A
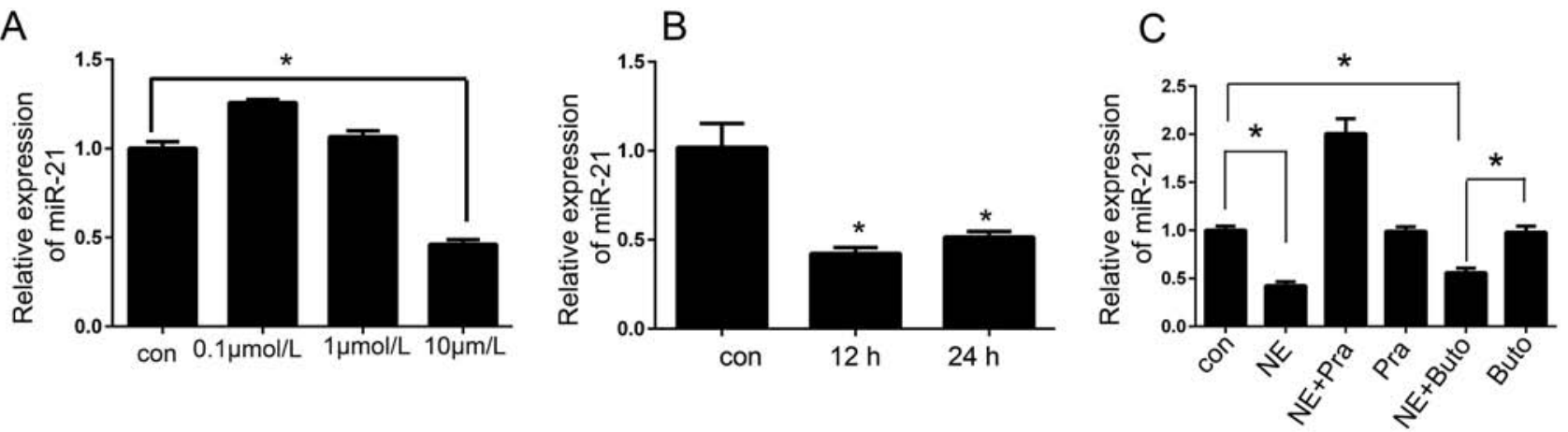

D

E
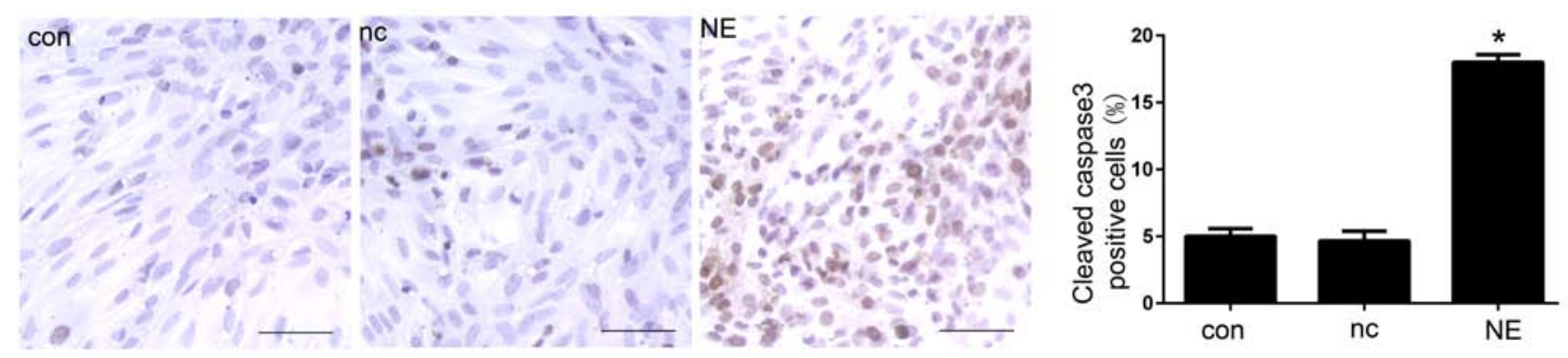

Figure 2

NE regulates the expression of miR-21 and induces granulosa cells apoptosis. (A) Quantification of miR-21 level after treatment (for $24 \mathrm{~h}$ ) with different levels of $\mathrm{NE}(0,0.1,1$ and $10 \mu \mathrm{mol} / \mathrm{L})$. con: control. The experiments were repeated at least three times and normalized to their respective control. Data are shown as means \pm S.E.M. $(n \geq 3) .{ }^{*} P<0.05 ;{ }^{*} P<0.01$. (B) miR-21 levels after being treated with $10 \mu \mathrm{mol} / \mathrm{L}$ NE for 0,12 and $24 \mathrm{~h}$. The experiments were repeated at least three times and normalized to their respective control. Data are shown as means \pm S.E.M. $(n \geq 3)$. $* P<0.05$. (C) The relative level of miR-21 in granulosa cells treated with $10 \mu \mathrm{mol} / \mathrm{L} \mathrm{NE}$ and two adrenergic receptor inhibitors. The control (con) was a vehicle control (PBS). The inhibitors for AR- $\alpha 1$ and AR- $\beta 2$ are prazosin (Pra) and butoxamine (Buto) respectively. The data are shown as means \pm s.E.M. For multiple separate transfections $(n=3) ;{ }^{*} P<0.05$. (D) Granulosa cells apoptosis was measured by using cleaved caspase3 analysis after treatment with NE for $24 \mathrm{~h}$. (E) Percentages of cleaved caspase3-positive cells accounting for the total granulosa cells. All scale bars represent $50 \mu \mathrm{m}$.

\section{miR-21 mediates the NE signaling pathway influencing granulosa cell apoptosis}

To confirm that miR-21 is involved in the NE signaling pathway, the endogenous miR-21 in cultured granulosa cells was inhibited and also overexpressed by a miR-21 inhibitor and miR-21 mimics, respectively. The results show that the miR-21 inhibitor downregulated the endogenous miR-21 by $71.6 \%$, whereas the mimics upregulated miR-21 expression 8.9-fold (Fig. 3A). Cultured granulosa cells were transfected with miR-21-mi and miR-21-in for $24 \mathrm{~h}$ and then treated with $10 \mu \mathrm{mol} / \mathrm{L} \mathrm{NE}$ for $24 \mathrm{~h}$, and then the relative gene expressions of Bax/ Bcl-2 were determined (Fig. 3B and C) and the cleaved caspase3-positive cells were counted. The results show that miR-21-in increased both basal and NE-enhanced granulosa cell apoptosis (Fig. 3D and F). We also found that, as expected, NE increased granulosa cell apoptosis in cells transfected with negative control mimics, but this effect vanished in the cells that overexpressed miR-21 mimics (Fig. 3E and G). These results demonstrate that
miR-21 negatively regulates the NE stimulatory action on granulosa cell apoptosis.

\section{Smad7 is the direct target gene of miR-21 in rat granulosa cells}

To find the target molecules of miR-21 affecting cell apoptosis, we used miRBase Targets and TargetScan to find targeting candidates of miR-21. We found two putative target genes: Jag1 and Smad7. In addition, Smad7 had also been shown to function as an apoptosis inducer in granulosa cells and the $3^{\prime}$ UTR of the Smad7 gene contains a highly conserved region that is a putative binding site for miR-21.

We then identified the interactions between miR-21 and its putative target genes, Jag1 and Smad7 using the 3'-UTR of Jag1 and Smad7 mRNA as the predicted binding site (Fig. 4A). Using psiCHECK-2, we cloned the putative 3'-UTR target site downstream of a luciferase reporter gene. We then co-transfected into 293T cells, the psiCHECK-2

Published by Bioscientifica Ltd. 
A

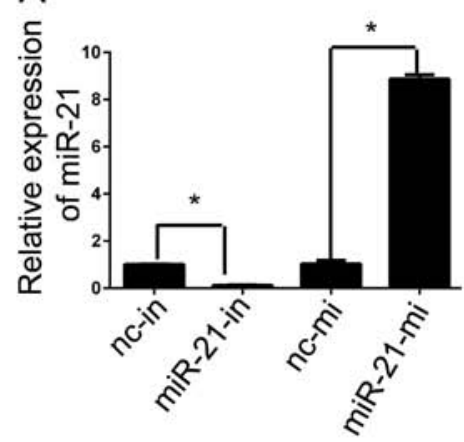

D

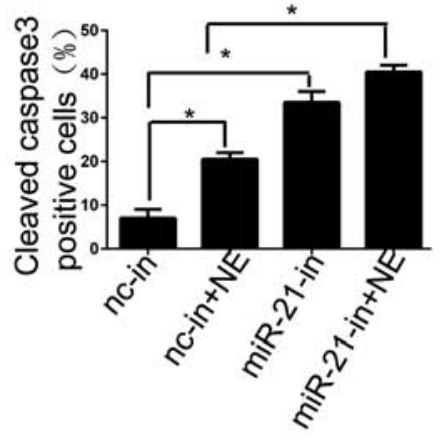

B
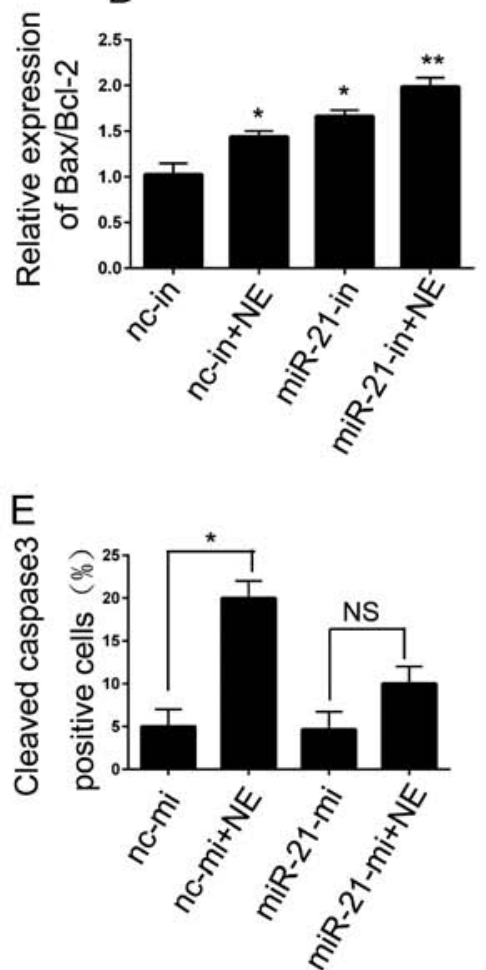

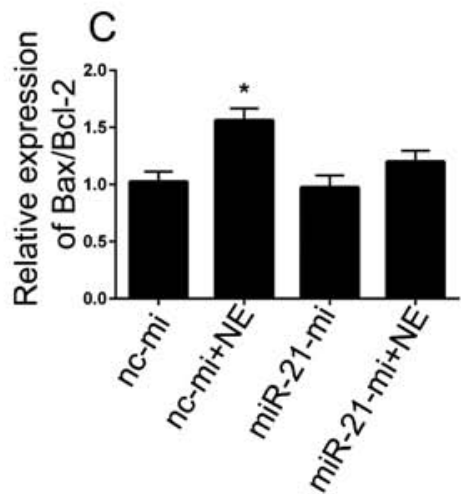

Rosițve control $: \because \because \because \because$

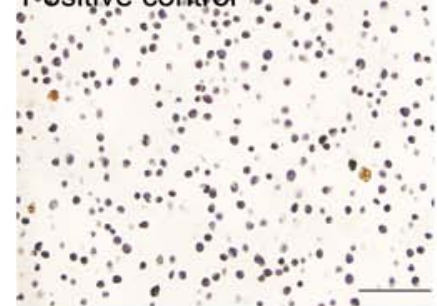

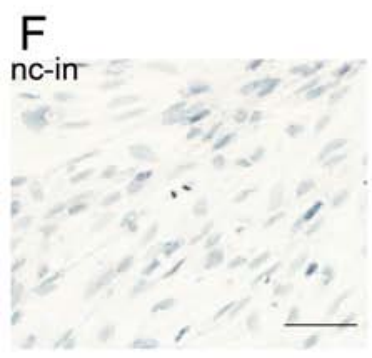

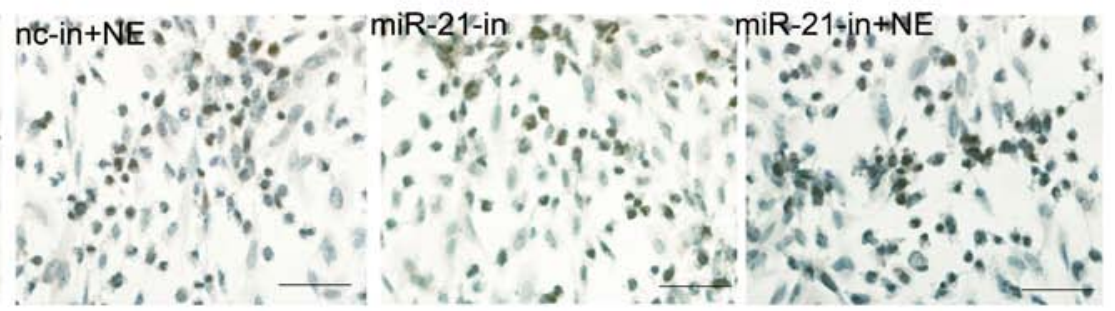

G
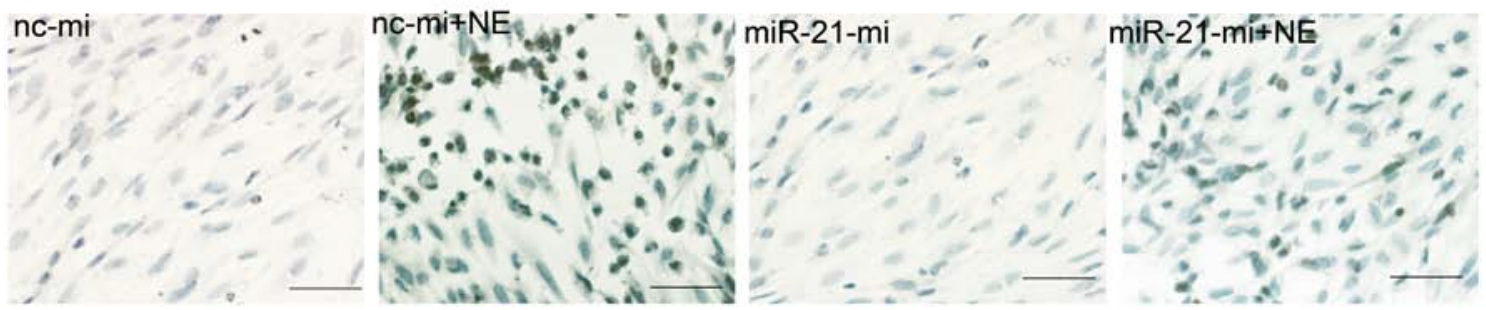

Figure 3

miR-21 mediates the signaling pathway that influences granulosa cell apoptosis. (A) Overexpression and inhibition efficiency of miR-21 mimics or inhibitor, transfected into granulosa cells after $24 \mathrm{~h}$. nc-in/nc-mi, miRNA inhibitor/mimics nonsense control; inhibitor, miR-21 inhibitor; mimics, miR-21 mimics. The data are means \pm S.E.M. for multiple separate transfections $(n=3)$. ${ }^{*} P<0.05$. (B) and $(C)$ relative gene expression of $B a x / B c l-2$. Granulosa cells were transfected with nc-in, miR-21-in, nc-mi and miR-21-mi, respectively, for $6 \mathrm{~h}$. We then added $10 \mu \mathrm{mol} / \mathrm{L}$ NE for $24 \mathrm{~h}$. Data are presented as means \pm S.E.M. $(n=3) * P<0.05 ; * * P<0.01$ (ANOVA). (D) and (E) percentages of cleaved caspase3-positive cells accounting for the total granulosa cells. Data are presented as means \pm S.E.M. $(n=3) * P<0.05$; (ANOVA). (F) and (G) light microscopy pictures of granulosa cell apoptosis measured by using cleaved caspase 3 analysis. Granulosa cells were transfected with nc-in, miR-21-in, nc-mi and miR-21-mi, respectively, for $6 \mathrm{~h}$. We then added $10 \mu \mathrm{mol} / \mathrm{L}$ NE for $24 \mathrm{~h}$. All scale bars represent $50 \mu \mathrm{m}$. 
A
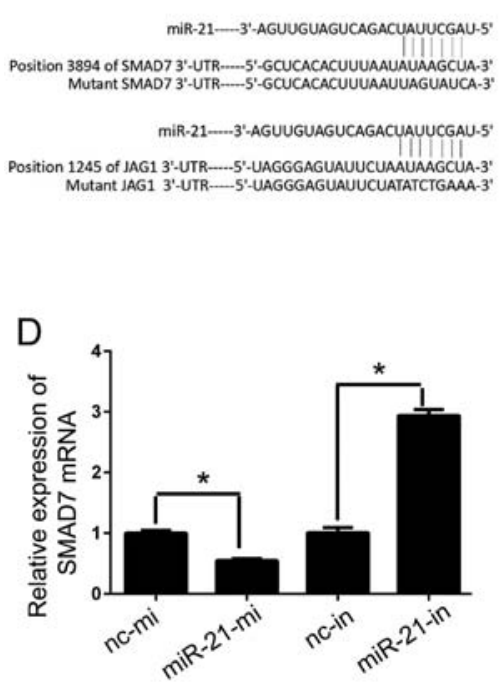
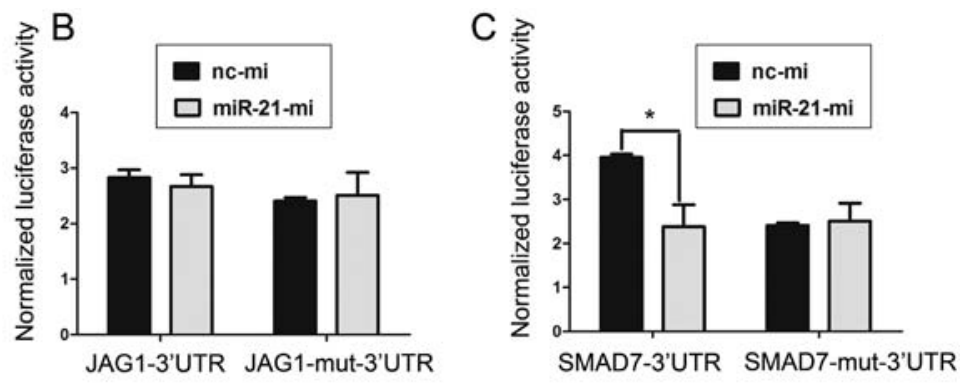

E

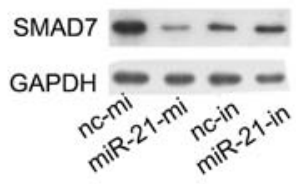

$\mathrm{F}$

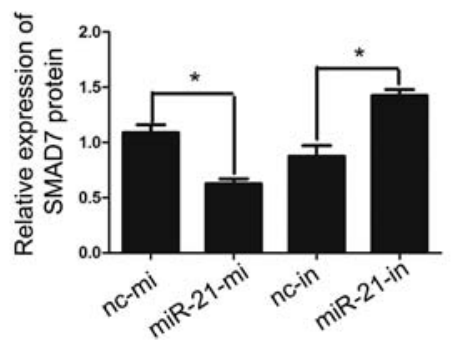

\section{Figure 4}

miR-21 binds to Smad7 3'UTR and downregulates its protein level. (A) The predicted miR-21-binding site is in the Smad7 and Jag1 3'UTRs. The data were taken from Sanger's miRNA target database. (B) and (C) relative luminescence intensity detected by the Modulus TMII microplate multimode reader after miR-21-mi nc mimics (nc-mi) and Dual-Luciferase vectors were co-transfected into 293T cells. The data are mean \pm s.E.M. for multiple separate transfections $(n=4)$; ${ }^{*}<0.05$. (D) Relative quantification of Smad7 mRNA levels. Primary granulosa cells were transfected with nc inhibitor (nc-in), miR-21 in, nc mimics (nc-mi), and miR-21-mi. These data are means \pm s.E.M. for multiple separate transfections ( $n=4)$. * $P<0.05$. (E) Analysis of SMAD7 protein levels. Primary granulosa cells were transfected as shown previously and protein extracts were analyzed by Western blotting. Results are mean \pm S.E.M. for multiple separate transfections $(n=4)$. (F) Quantification of SMAD7 protein levels. The data are means \pm S.E.M., $* P<0.05 ;(S A S 9.0)$.

(wild type or mutant) together with miR-21-mi or negative control (nc) mimics. The results showed that the luciferase activity of the transfected cells with miR-21-mi and 3'-UTR-Smad7 decreased by $\sim 39 \%$ compared with the cells co-transfected with the nc mimic and $3^{\prime}$-UTR-Smad7. The negative control construct of mutations in the $3^{\prime}$ UTR of Smad7 (3'-UTR-MUT-Smad7) showed no obvious change in luciferase activity (Fig. 4C). 3'-UTR-JAG1 construct of luciferase activity did not change compared with mutations in the 3'-UTR of Jag1 (3'-UTR-MUT-Jag1) (Fig. 4B). Further functional analysis indicated that miR21 overexpression in rat granulosa cells resulted in a reduction of Smad7 mRNA and protein levels, whereas the inhibition of miR-21 significantly increased Smad7 mRNA and protein levels (Fig. 4D, E and F). These results confirm that the Smad7 gene is a miR-21 target and that miR-21 regulates $S m a d 7$ gene expression at the transcriptional level (Fig. 4D).

\section{Smad7 is involved in the signaling pathway of NE that regulates granulosa cell apoptosis}

To identify whether Smad7 is involved in the signaling pathway of NE that regulates granulosa cells apoptosis, we treated rat granulosa cell with 0 (control), 0.1, 1 and $10 \mu \mathrm{mol} / \mathrm{L}$ NE for $24 \mathrm{~h}$, and Smad7 expression was assayed. The results show that $10 \mu \mathrm{mol} / \mathrm{L}$ NE upregulated Smad7 mRNA significantly (Fig. 5A). Western blot analysis confirmed that $10 \mu \mathrm{mol} / \mathrm{L}$ NE significantly upregulates SMAD7 protein levels (Fig. 5B and C). We then used three different Smad7 siRNAs and chose Smad7 siRNA3, which had a higher inhibition on cleaved caspase3 protein (Fig. 5D). Smad7 siRNA also inhibited the effect of NE on cleaved caspase 3 protein level by 37\% (Fig. 5E and F). These preliminary results demonstrate that $S m a d 7$ plays an important role in mediating the regulatory effect of $\mathrm{NE}$ on rat granulosa cell apoptosis.

\section{NE enhances apoptosis mediated by TGF- $\beta$ in granulosa cells}

The previously mentioned data show that $S m a d 7$ is a miR-21 target in rat ovaries. It is also known that SMAD7 is a general antagonist for TGF- $\beta$ signaling (Yan et al. 2009). We hypothesized that NE is involved in TGF- $\beta$ signaling. To confirm this, primary granulosa cells were treated with NE, TGF- $\beta$ or a combination of NE and TGF- $\beta$. The results show that NE or TGF- $\beta$ treatment decreased miR-21

Published by Bioscientifica Ltd. 
A

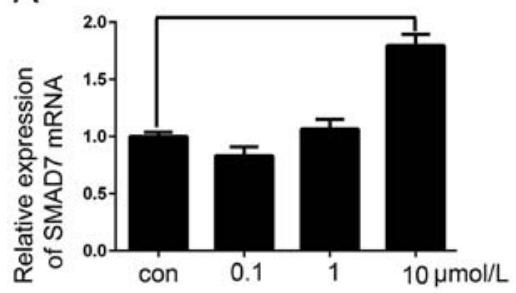

D

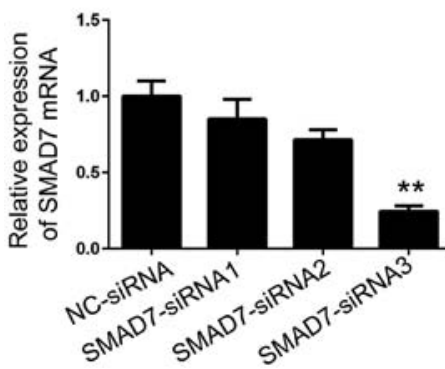

B

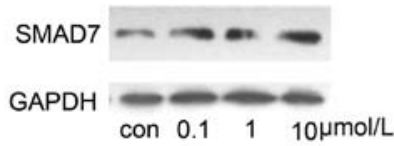

con $0.1110 \mu \mathrm{mol} / \mathrm{L}$

E

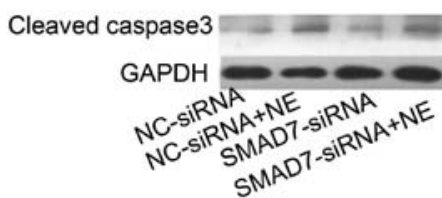

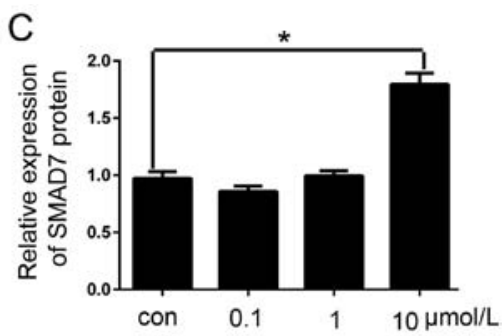

F

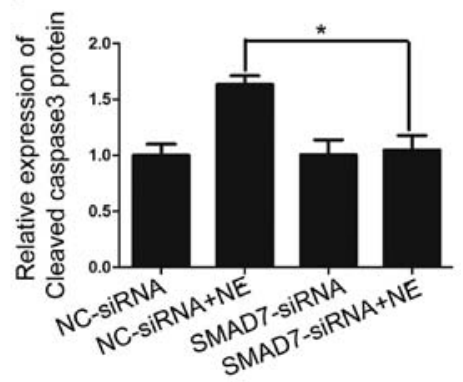

\section{Figure $\mathbf{5}$}

SMAD7 is involved in the signaling pathway of NE that regulates granulosa cells apoptosis. (A) Quantification of SMAD7 mRNA levels after being treated with different levels of $\mathrm{NE}(0,0.1,1$ and $10 \mu \mathrm{mol} / \mathrm{L})$. The experiments were repeated at least three times and normalized to their respective control. Data are shown as means \pm S.E.M. $(n \geq 3)$. $* P<0.05$. (B) SMAD7 protein expression levels were analyzed by Western blotting. (C) Quantification of SMAD7 protein levels. Data are presented as means \pm s.E.M. $(n=3) .{ }^{*} P<0.05$. (D) Quantification of intracellular $S M A D 7$ mRNA levels after the granulosa cells were transfected with SMAD7 siRNA1-3 for $24 \mathrm{~h}$. Data are presented as mean \pm s.E.M. $(n=3)\left({ }^{*} P<0.05\right.$, by ANOVA). (E) Cleaved caspase 3 protein expression levels were analyzed by Western blotting. The granulosa cells were transfected with nc siRNA or SMAD7 siRNA and $24 \mathrm{~h}$ later, $10 \mu \mathrm{mol} / \mathrm{L}$ NE was added to granulosa cells and were treated for $24 \mathrm{~h}$. (F) Quantification of cleaved caspase3 protein levels. Data are presented as means \pm S.E.M. $(n=3)$. ${ }^{*} P<0.05$.

expression 3- and 4-fold, respectively, whereas treatment with a combination of NE and TGF- $\beta$ decreased miR-21 expression by approximately 10-fold (Fig. 6A), indicating that NE has an additive effect on TGF- $\beta$ signaling. We then detected Smad7 mRNA levels and SMAD7 protein levels in these four treatment groups (control, NE, TGF- $\beta$ and NE+TGF- $\beta$ ). The results showed that both Smad7 mRNA levels and protein levels increased (Fig. 6B, C and D). These data indicated that NE enhances TGF- $\beta$ induced granulosa cell apoptosis.

\section{Discussion}

NE has been shown to be involved in many regulatory aspects of ovary functions, including early follicular development (Mayerhofer et al. 1997) and the importance of its interrelation on the ovarian steroidogenesis and apoptosis on dioestrus II in rat (Bronzi et al. 2015). Several recent reports have shown that NE acts on $\beta 2$-adrenergic receptors present in granulosa cells from the rat ovary and stimulates the production of progesterone, but not the secretion of estradiol (Lawrence \& Burden 1980, Skarzynski 1993, Lara et al. 2002). NE may also facilitate the follicular development, as seen, for example, in the inhibition of follicular growth after ovarian denervation (Mayerhofer et al. 1997, Doganay et al. 2010). In this study, we identified miRNA expression profiles of NE-stimulated rat granulosa cells for the first time. Furthermore, miR-21 was shown to play an important role in NE-induced granulosa cell apoptosis by targeting Smad7. The findings of this study provide initial evidence that miR-21 participates in regulating rat granulosa cells apoptosis by targeting Smad7. A direct link between miRNAs and NE during ovarian follicle development has also been established for the first time.

miRNAs have been shown to play important roles in several biological events. For example, miR-378 is involved in regulating ovarian estradiol production by targeting aromatase ( $\mathrm{Xu}$ et al. 2011) and miR-181a has been reported to play a role in mouse granulosa cell proliferation (Zhang et al. 2013). The regulating effects of the miR-21 on granulosa cell apoptosis have been previously reported (Carletti et al. 2010). However, a functional relationship between NE and miR-21 has not been established for regulating granulosa cell apoptosis. Our results demonstrate that adrenergic receptors and miR-21 are expressed in rat granulosa cells. And the expression of miR-21 is decreased in the ovary from the

Published by Bioscientifica Ltd 

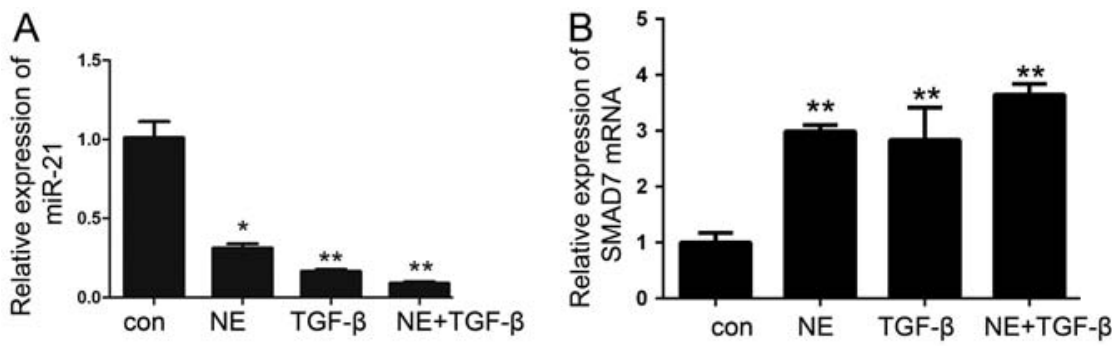

C

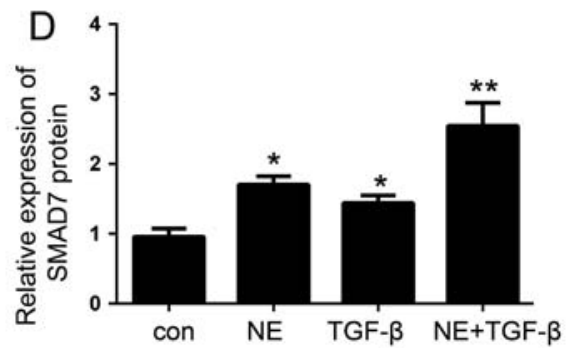

\begin{abstract}
Figure 6
NE enhances apoptosis mediated by TGF- $\beta$ in granulosa cells. SMAD7 mRNA and protein levels along with miR-21 expression were detected after primary granulosa cells were treated with NE $(10 \mu \mathrm{mol} / \mathrm{L})$, TGF $-\beta(5 \mathrm{ng} / \mathrm{mL})$ or combination of $10 \mu \mathrm{mol} / \mathrm{L}$ NE and TGF $\beta$ for $24 \mathrm{~h}$. (A) Relative expression of miR-21 levels. Data are presented as means \pm S.E.M. $(n=4)\left({ }^{*} P<0.05 ; * * P<0.01\right.$, by $t$-test). (B) Expression levels of SMAD7 mRNA were measured by real-time PCR. Data are presented as means \pm S.E.M. $(n=4)(* P<0.05$, $* * P<0.01$, by $t$-test). (C) SMAD7 protein levels were detected by Western blot. (D) Quantification of KRAS protein levels. Data are presented as means \pm S.E.M. $(n=3)(* P<0.05$, $* * P<0.01$, by ANOVA).
\end{abstract}

animal model for study the follicular atresia. Therefore, miR-21 may be associated with follicular atresia. One of the prominent features of follicular atresia is granulosa cell apoptosis. In addition, our functional experiments have demonstrated that addition of $10 \mu \mathrm{mol} / \mathrm{L}$ NE significantly inhibits miR-21 expression. In addition, NE treatment significantly increased granulosa cell apoptosis.

NE, a known sympathetic neurotransmitter, regulates sympathetic nerve activities. It is also well documented that NE induced cultured rat cardiomyocyte apoptosis (Ma et al. 2013). The report (Bronzi et al. 2015) has demonstrated the importance of its interrelation on the ovarian steroidogenesis and apoptosis on dioestrus II in rat. However, the apoptotic pathway of NE regulating ovarian granulosa cell is unknown. The previous report (Greiner et al. 2008) shows that ovarian non-neuronal, endocrine granulosa cells can take up NE, and then serve as an intrafollicular catecholamine-storing compartment. In this study, NE was shown to regulate ovarian functions by targeting miR-21 and acting on AR- $\alpha_{1 A}$ in cultured granulosa cells. To investigate the roles of miR-21 in NE-induced granulosa cell apoptosis, miR-21 was functionally characterized in rat granulosa cells. Our results show that knockdown of miR-21 induces rat granulosa cell apoptosis and enhances NE-induced granulosa cell apoptosis. From the previously mentioned results, we can state that miR-21 controls reproductive functions by blocking rat granulosa cell apoptosis, either alone or in combination with NE.

Smad7, the gene target of miR-21, was identified to account for the previously mentioned phenotype. SMAD7, a critical factor of the TGF- $\beta$ signaling pathway, has been shown to induce apoptosis in granulosa cells
(Quezada et al. 2012). Forced expression of miR-21 and knockdown of miR-21 in granulosa cells decreased and increased Smad7 mRNA and protein expression levels, respectively. Additionally, Smad7 siRNA attenuated miR-21 inhibitor-induced rat granulosa cell apoptosis. These results confirm that Smad7 is a target of miR-21. We identified that Smad7 is involved in the signaling pathway of NE that regulated granulosa cells apoptosis.

Smad7, a common mediator of TGF- $\beta$ signaling, has been suggested to play an important role in the regulation of ovarian follicle growth and female fertility. One study reported that $S m a d 7$ expression is upregulated by treating with TGF- $\beta$, and the overexpression of Smad7 induces granulosa cell apoptosis (Quezada et al. 2012). This result is consistent with ours. Our results demonstrated that $10 \mu \mathrm{mol} / \mathrm{L}$ NE increases SMAD7 protein expression by the knockdown of miR-21 and that Smad7 mediates the roles of miR-21 thus influencing granulosa cell apoptosis. We also demonstrated that miR-21 blocks cell apoptosis by targeting Smad7. These results not only validate the functional relevance of $\operatorname{Smad7}$ (a target gene of miR-21) in NE/miR-21-stimulated rat granulosa cells but also provide a new molecular mechanism of NE's regulation of Smad7.

In conclusion, we have revealed that miR-21 is expressed in the rat ovary and is located in the granulosa cells. Additionally, miR-21 acts as a negative mediator to regulate NE-induced granulosa cell apoptosis by targeting Smad7. In the light of our study, due to the functions of miR-21 in granulosa cells, it is worth pursuing research into using it as a novel target for physiological or pharmacological interventions in diseases such as polycystic ovarian syndrome (PCOS).

Published by Bioscientifica Ltd. 


\section{Declaration of interest}

The authors declare that there is no conflict of interest that could be perceived as prejudicing the impartiality of the research reported.

\section{Funding}

This work was supported by the Natural Science Foundation of China (31172288)

\section{Author contribution statement}

Sheng Cui conceived and designed the experiments; Li Zhang and Jie Gao carried out the experiments; Li Zhang analyzed the data; Jie Gao provided the reagents/materials/analysis tools and Sheng Cui and Li Zhang wrote the manuscript.

\section{References}

Briones-Orta MA, Tecalco-Cruz AC, Sosa-Garrocho M, Caligaris C \& Macias-Silva M 2011 Inhibitory Smad7: emerging roles in health and disease. Current Molecular Pharmacology 4 141-153. (doi:10.2174/1874 467211104020141)

Bronzi CD, Orozco AS, Rodriguez D, Rastrilla AM, Sosa ZY \& Casais M 2015 Noradrenaline modulates the presence of gonadotropinreleasing hormone in ovary. The importance of its interrelation on the ovarian steroidogenesis and apoptosis on dioestrus II in rat. Journal of Steroid Biochemistry and Molecular Biology 154 39-46. (doi:10.1016/j.jsbmb.2015.06.005)

Carletti MZ, Fiedler SD \& Christenson LK 2010 MicroRNA 21 blocks apoptosis in mouse periovulatory granulosa cells. Biology of Reproduction 83 286-295. (doi:10.1095/biolreprod.109.081448)

D'Albora H, Anesetti G, Lombide P, Dees WL \& Ojeda SR 2002 Intrinsic neurons in the mammalian ovary. Microscopy Research and Technique 59 484-489. (doi:10.1002/jemt.10231)

Doganay M, Simsek A, Tapisiz OL, Mulazimoglu BS, Yumusak N \& Gungor T 2010 Superior ovarian nerve (SON) transection leads to stunted follicular maturation: a histomorphologic and morphometric analysis in the rat model. Fertility and Sterility 93 1711-1714. (doi:10.1016/j.fertnstert.2009.09.026)

Donadeu FX, Schauer SN \& Sontakke SD 2012 Involvement of miRNAs in ovarian follicular and luteal development. Journal of Endocrinology 215 323-334. (doi:10.1530/JOE-12-0252)

Fiedler SD, Carletti MZ, Hong X \& Christenson LK 2008 Hormonal regulation of MicroRNA expression in periovulatory mouse mural granulosa cells. Biology of Reproduction 79 1030-1037. (doi:10.1095/ biolreprod.108.069690)

Greiner M, Paredes A, Rey-Ares V, Saller S, Mayerhofer A \& Lara HE 2008 Catecholamine uptake, storage, and regulated release by ovarian granulosa cells. Endocrinology 149 4988-4996. (doi:10.1210/en.20071661)

Hanoux V, Pairault C, Bakalska M, Habert R \& Livera G 2007 Caspase-2 involvement during ionizing radiation-induced oocyte death in the mouse ovary. Cell Death and Differentiation 14 671-681. (doi:10.1038/sj.cdd.4402052)
Lara HE, Dorfman M, Venegas M, Luza SM, Luna SL, Mayerhofer A, Guimaraes MA, Rosa ESAA \& Ramirez VD 2002 Changes in sympathetic nerve activity of the mammalian ovary during a normal estrous cycle and in polycystic ovary syndrome: Studies on norepinephrine release. Microscopy Research and Technique 59 495-502. (doi:10.1002/jemt.10229)

Lawrence IE Jr \& Burden HW 1980 The origin of the extrinsic adrenergic innervation to the rat ovary. Anatomical Record 196 51-59. (doi:10.1002/ar.1091960106)

Ma YX, Guo Z \& Sun T 2013 CGRP inhibits norepinephrine induced apoptosis with restoration of $\mathrm{Bcl}-2 / \mathrm{Bax}$ in cultured cardiomyocytes of rat. Neuroscience Letters 549 130-134. (doi:10.1016/j. neulet.2013.05.028)

Mayerhofer A, Dissen GA, Costa ME \& Ojeda SR 1997 A role for neurotransmitters in early follicular development: induction of functional follicle-stimulating hormone receptors in newly formed follicles of the rat ovary. Endocrinology 138 3320-3329. (doi:10.1210/ en.138.8.3320)

Obernosterer G, Martinez J \& Alenius M 2007 Locked nucleic acid-based in situ detection of microRNAs in mouse tissue sections. Nature Protocols 2 1508-1514. (doi:10.1038/nprot.2007.153)

Otsuka M, Zheng M, Hayashi M, Lee JD, Yoshino O, Lin S \& Han J 2008 Impaired microRNA processing causes corpus luteum insufficiency and infertility in mice. Journal of Clinical Investigation 118 1944-1954. (doi:10.1172/JCI33680)

Park SH 2005 Fine tuning and cross-talking of TGF-beta signal by inhibitory Smads. Journal of Biochemistry and Molecular Biology 38 9-16. (doi:10.5483/bmbrep.2005.38.1.009)

Quezada M, Wang J, Hoang V \& McGee EA 2012 Smad7 is a transforming growth factor-beta-inducible mediator of apoptosis in granulosa cells. Fertility and Sterility 97 1452-1459; e1451-e1456. (doi:10.1016/j.fertnstert.2012.03.024)

Skarzynski D 1993 Mechanism of norepinephrine influence on the secretion of ovarian oxytocin and progesterone in conscious cattle. Journal of Reproduction and Fertility 97 419-424. (doi:10.1530/ jrf.0.0970419)

Teng Z, Wang C, Wang Y, Huang K, Xiang X, Niu W, Feng L, Zhao L, Yan H, Zhang H, et al. 2015 S100A8, an oocyte-specific chemokine, directs the migration of ovarian somatic cells during mouse primordial follicle assembly. Journal of Cellular Physiology 230 2998-3008. (doi:10.1002/jcp.25032)

Xu S, Linher-Melville K, Yang BB, Wu D \& Li J 2011 Micro-RNA378 (miR-378) regulates ovarian estradiol production by targeting aromatase. Endocrinology 152 3941-3951. (doi:10.1210/en.20111147)

Yan X, Liu Z \& Chen Y 2009 Regulation of TGF-beta signaling by Smad7. Acta Biochimica et Biophysica Sinica 41 263-272. (doi:10.1093/ abbs/gmp018)

Yao G, Yin M, Lian J, Tian H, Liu L, Li X \& Sun F 2010 MicroRNA-224 is involved in transforming growth factor-beta-mediated mouse granulosa cell proliferation and granulosa cell function by targeting Smad4. Molecular Endocrinology 24 540-551. (doi:10.1210/me.20090432)

Zhang Q, Sun H, Jiang Y, Ding L, Wu S, Fang T, Yan G \& Hu Y 2013 MicroRNA-181a suppresses mouse granulosa cell proliferation by targeting activin receptor IIA. PLOS ONE 8 e59667. (doi:10.1371/ journal.pone.0059667)

Received in final form 24 March 2017

Accepted 29 March 2017 http://jme.endocrinology-journals.org

DOI: 10.1530/JME-16-0248
() 2017 Society for Endocrinology Printed in Great Britain
Published by Bioscientifica Ltd 